
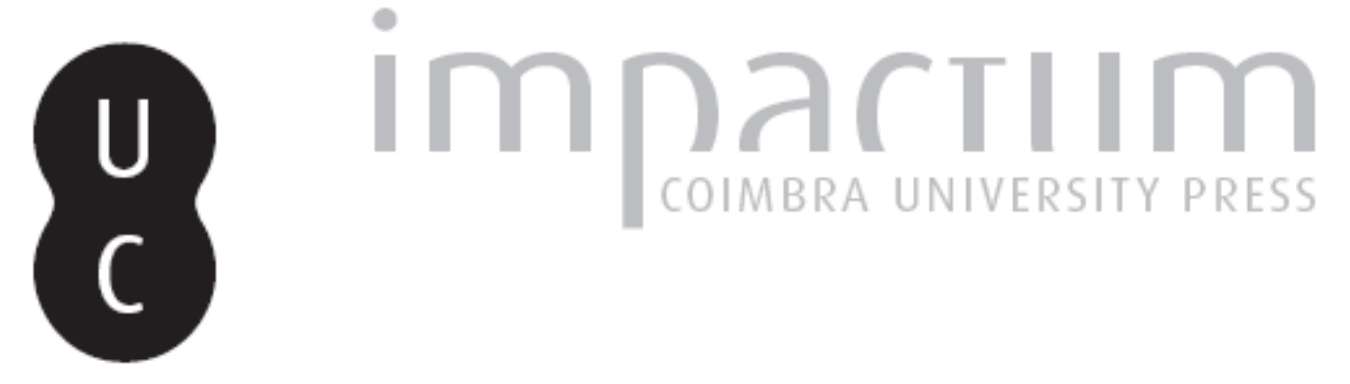

\title{
Conflitos violentos entre a Coroa e a Mitra em Coimbra no século XIII
}

\section{Autor(es): $\quad$ Veloso, Maria Teresa Nobre}
Publicado por: Instituto de História Económica e Social; Imprensa da Universidade de Coimbra

URL persistente:

URI:http://hdl.handle.net/10316.2/44505

DOI:

DOI:https://doi.org/10.14195/0870-4147_37_13

Accessed : $\quad$ 26-Apr-2023 08:07:18

A navegação consulta e descarregamento dos títulos inseridos nas Bibliotecas Digitais UC Digitalis, UC Pombalina e UC Impactum, pressupõem a aceitação plena e sem reservas dos Termos e Condições de Uso destas Bibliotecas Digitais, disponíveis em https://digitalis.uc.pt/pt-pt/termos.

Conforme exposto nos referidos Termos e Condições de Uso, o descarregamento de títulos de acesso restrito requer uma licença válida de autorização devendo o utilizador aceder ao(s) documento(s) a partir de um endereço de IP da instituição detentora da supramencionada licença.

Ao utilizador é apenas permitido o descarregamento para uso pessoal, pelo que o emprego do(s) título(s) descarregado(s) para outro fim, designadamente comercial, carece de autorização do respetivo autor ou editor da obra.

Na medida em que todas as obras da UC Digitalis se encontram protegidas pelo Código do Direito de Autor e Direitos Conexos e demais legislação aplicável, toda a cópia, parcial ou total, deste documento, nos casos em que é legalmente admitida, deverá conter ou fazer-se acompanhar por este aviso.

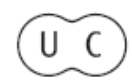




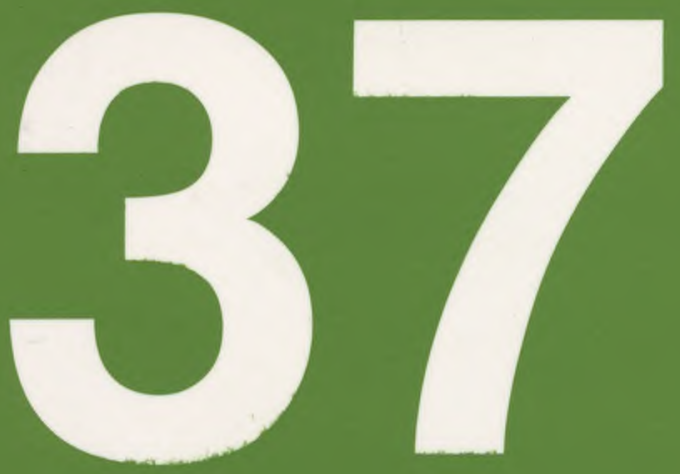

Revista Portuguesa de História

Faculdade de Letras da Universidade de Coimbra Instituto de Historia Econónica e Samial

Coimbra 05 


\section{Conflitos violentos entre a Coroa e a Mitra em Coimbra no século XIII}

Maria Teresa Nobre Veloso Faculdade de Letras da Universidade de Coimbra

"(•••) Domnus Petrus visum fuit ei tunc in aspectu occulorum suorum quod non erat sane mentis (..

A loucura de D. Pedro Soares, várias vezes citada mas nunca pormenorizadamente estudada, é o reflexo inequívoco dos conflitos violentos travados não só entre clérigos (seculares, regulares e religioso-militares), mas principalmente entre a Coroa e a Mitra. No século XIII estes assumem a sua máxima intensidade, mercê das transformações politico-culturais que então se operavam na Europa, e cujos protagonistas em Portugal são, de modo particular, os reis D. Sancho I, D. Afonso II, o influentíssimo chanceler de ambos - mestre Julião Pais - e o bispo de Coimbra.

Neste estudo procuraremos demonstrar como D. Pedro Soares, defensor acérrimo das liberdades eclesiásticas, lutou denodadamente com todos os instrumentos legais ao seu alcance, durante pelo menos três décadas, pela defesa dos direitos da sua prestigiada Catedral. A exposição prolongada (o seu 1

1 Depoimento do cónego mestre Bartolomeu no Inquérito de c. 1252. Cfr. infra, nota 29. 
episcopado durou cerca de quarenta anos) $)^{2}$ aos violentos conflitos e aos infindáveis litígios que teve que enfrentar, o sem número de humilhações (às quais não faltou a prisão) com que a Coroa o esmagou, provocaram no bispo conimbricense inequívocos sinais de perturbação mental que acabará por levar à renúncia do prelado nas mãos do Santo Padre.

D. Pedro Soares, que ascendeu à cátedra episcopal de Coimbra em 1192, era proveniente de uma família ilustre certamente natural desta região. Segundo o Livro das Calendas, ficamos a saber que ele possuía bens em Espinho (c. Condeixa-a-Nova) e que era irmão de Martinho Soares também proprietário nesta vila. O sobrinho do citado bispo, D. Pedro Martins, era mestre-escola na Sé de Coimbra e o recém-eleito prelado exercera as funções de prior desta Igreja $^{3}$. Uma vez que a tais dignidades do Cabido só ascendiam homens bem colocados socialmente como acontecia, na mesma Catedral, com os parentes de mestre Julião Pais (D. Gonçalo Dias e mestres Julião e Gil), sem dificuldade podemos concluir pela importância da família de D. Pedro Soares.

A Igreja que este iria governar cerca de quarenta anos, e que fora a mais notável instituição religiosa da zona Centro do país, vivia momentos difíceis. Os golpes que diariamente lhe eram desferidos, não só pelo poder temporal

2 D. Pedro Soares teve um longo episcopado que durou de 1192 a 1232.0 primeiro diploma real em que aparece como subscritor data de Julho de 1192. Cfr. Documentos de D. Sancho I (1174-1211). Editores: Rui de Azevedo; P. Avelino de Jesus da Costa; Marcelino Rodrigues Pereira. Coimbra : Centro de História da Universidade de Coimbra, 1979 (= D. D. 5.), doc. 59. A 25 de Julho de 1232, Gregorio IX na bula Tanta est clavis, dirigida ao arcebispo de Braga, ao referir-se ao prelado de Coimbra já o menciona como "quondam episcopus Colimhriensis. Cfr. COSTA, António Domingues de Sousa - Mestre Silvestre e Mestre Vicente, juristas de D. Afonso II e suas irmãs. Braga : Editorial Franciscana, 1963, p. 188, nota 304 que transcreve esta bula. Citaremos sempre esta obra por Mestre Silvestre e Mestre Vicente.

3 Cfr. assento de óbito de Martinho Soares datado de 8 de Maio de 1223 in Liber Anniversariorum Ecclesiae Cathedralis Colimbrie $=$ L. K.. Editores: Pierre David; Torquato de Sousa Soares. Coimbra : Instituto de Estudos Históricos Dr. António de Vasconcelos, MDCCCCXLVII, T. I., p. 236-237. Cfr. igualmente o assento de óbito de D, Pedro Soares com data de 23 de Dezembro de $1233 \mathrm{em} \mathrm{L.} \mathrm{K.,} \mathrm{T.} \mathrm{II,} \mathrm{p.} \mathrm{322-323.} \mathrm{A} 22$ de Junho de 1233 acha-se um outro assento de óbito deste prelado de Coimbra. Miguel Ribeiro de Vasconcellos, no século XIX, escreveu a seguinte nota relativamente a esta questão: "Creio que este (o de 22 de Junho) será para lembrança do aniversário que seu sobrinho deixou por sua alma". Cfr. L. K., T. I, p. 306-307. Sobre os bens deixados por D. Pedro Soares à Sé de Coimbra, cfr. NOGUEIRA, Pedro Alvares - Livro das vidas dos bispos da Sé de Coimbra. Nova Edição. Coordenação de Manuel Augusto Rodrigues. Transcrição de Maria Teresa Nobre Veloso. Coimbra : Arquivo da Universidade de Coimbra, 2003, p. 85 e VASCONCELLOS, Miguel Ribeiro de - "Notícia histórica do mosteiro da Vacariça..." in Memorias da Academia Real das Sciendas. Lisboa: 1857.1. 2, parte 2, p. 4. 
que tanto a engrandecera, como também pelo poder espiritual, ao abrigo da nova política pontifícia apostada em retirar aos bispos toda a sua influência ${ }^{4}$, obrigaram o prelado a uma vigilância constante, a uma gestão diligente e empenhada da sua vasta diocese e, sempre que necessário, a uma luta tenaz, sem tréguas nem desfalecimento, pela preservação do imenso património que lhe fora confiado ${ }^{5}$.

Dos inúmeros conflitos que teve que enfrentar avultam, pela inusitada violência de que se revestiram, os que travou com os cónegos agostinhos de Santa Cruz de Coimbra ${ }^{6}$ e principalmente aqueles que manteve com D. Sancho I e D. Afonso H.

No advento do século XIII vivia-se no Ocidente sob o timbre de significativas transformações. Estas que resultavam, em parte, do êxito da Reforma Gregoriana, cuja marca mais expressiva era a centralização do poder pontifício, preconizavam, entre outras medidas, a perda de influência dos bispos. A sua auctoritas, misto de sapientia et misericordia ${ }^{7}$, conferia-lhes um prestígio que não cessou de aumentar desde a queda do império romano. $\mathrm{Na}$ verdade, quando o poder político se desfez, foram os prelados que conduziram o Ocidente: acolheram as populações perseguidas, libertaram cativos, mataram a fome ao povo abrindo os celeiros episcopais, construíram e embelezaram igrejas, morigeraran! a brutalidade e a violência dos senhores mas, acima de tudo, estabeleceram os fundamentos de uma nova ordem quando, a partir do século X, promoveram as instituições de paz ${ }^{8}$. O reconhecimento público do prestígio episcopal está plasmado na quantidade de bispos que foram elevados aos altares como santos ${ }^{9}$.

4 Cfr. VEloso, Maria Teresa Nobre - D. Afonso II. Relações de Portugal com a Santa Sé durante o seu reinado. Coimbra : Arquivo da Universidade de Coimbra, 2000, p. 223-228.

5 A diocese de Coimbra era um extenso território que se alargava desde a margem Sul do Douro (Vila Nova de Gaia) até ao Nabão e compreendia todas as terras situadas entre o Oceano e Cória (hoje província de Cáceres - Espanha).

6 O conflito entre a Sé de Coimbra (durante o episcopado de D. Pedro Soares) e o mosteiro de Santa Cruz está mencionado na documentação pontifícia entre 14 de Maio de 1198 e 25 de Abril de 1231. As fases mais violentas deste litígio foram estudadas por VELOSO, Maria Teresa Nobre - D. Afonso //, p. 240-254.

7 Sobre a ideia de auctoritas cfr. JÉGOU, Laurent - "L'évêque entre autorité sacrée et exercice du pouvoir. L'exemple de Gérard de Cambrai (1012-1051) in Cahiers de civilisation médiévale. X.e-XII. ${ }^{e}$ siècles. Poitiers : Centre d'Études Supérieures de Civilisation Médiévale, 47, Janvier -Mars 2004, p. 38-43.

8 Um dos trabalhos mais recentes sobre o protagonismo dos bispos na promoção das instituições de paz é o de GARCÍA FITZ, Francisco - La Edad Media: guerra e ideologia. Justificaciones religiosas y juridicas. Madrid : Sílex, 2003, p. 143-154.

9 Citamos apenas como exemplo ilustrativo os lugares de peregrinação (onde se venerava um santo prelado) mencionados no cap. VIII do Livro V do Codex Calistinus: S. Trófimo, S. Cesário e S. Honorato em Arles; S. Semin em Toulouse; S. Caprasio em Agen; S. Fronton em Périgueux; S. Evurcio em Orléans; S. Martinho em Tours; S. Hilário em Poitiers; S. Eutrópio em Saintes; 
Para diminuir a importância dos prelados, baseada no dito prestígio, a sé romana utilizou estratégias que passaram pela criação de outros poderes paralelos - mosteiros e religiosos isentos de pagamento de dízimos, de excomunhão, da jurisdição do ordinário... Neste âmbito, entre os finais do século XII e princípio do XIII, chamam particularmente a atenção, pelo inaudito grau de violência atingida, os litígios travados entre os bispos de Coimbra e os Templários. Os cavaleiros-monges confiantes, por um lado, na protecção régia que decorria da imprescindibilidade que eles representavam no avanço da Reconquista, e, por outro, no apoio que a Santa Sé lhes facultava ao transformá-los em agentes de missionação, ousaram receber, em Soure, não só o prelado conimbricense D. Miguel Salomão, mas também o legado pontifício, Pedro de S. Germano, "convida multa (...) et etiam lapides et stercora. A certeza de impunidade justificava a arrogância do seu comportamento ${ }^{10} 11$.

Porém, a questão mais grave teve-a D. Pedro Soares com os cónegos regrantes de Santa Cruz. No decurso do arrastado litígio (durou pelo menos de 1198-1231) que se ventilava na Santa Sé, mas no qual o rei D. Sancho I procurou intervir ${ }^{11}$,

S. Dinis em Paris; S. Severino em Bordéus; S. Isidoro em León. Cfr. LÓPEZ PEREIRA, Xosé Eduardo - Guia medieval do peregrino. Códice Calixtino, libro V. Estudio, edición e traducción. 2. ${ }^{\text {a edición. }}$ Salamanca : Edicións Xerais de Galicia, 1994, p. 97-121.

${ }^{10}$ Sobre a protecção pontifícia dada aos Templários e sobre o litígio havido entre D. Pedro Soares e os cavaleiros-monges, cfr. VELOSO, Maria Teresa Nobre - D. Afonso //, p. 229-231.

11 D. Sancho I, que como seu pai tinha grande apreço pelo mosteiro de Santa Cruz, diligenciou no sentido de fazer acordar as partes litigantes. Para esse fim chega ao ponto de tentar iniciar-se na complicada terminologia jurídica - "Et dominus rex: "Quid est hoc dicere assessores "(...) Tunc quesivit rex a magistro Martino quid est arbitri". Porém, face à contumácia revelada pelos contendores e "indignatus superfrivolitate verborum iratus surrecxif e exclamou indignado:

- "Episcopus habet episcopatum suum et prior prioratum suum et nolo ego inde sufferre laborem 1 Cfr. Bulário Português. Inocêncio III (1198-1216). Editores: Avelino de Jesus da Costa; Maria Alegria Femandes Marques. Coimbra : Instituto Nacional de Investigação Científica - Centro de Historia da Sociedade e da Cultura da Universidade de Coimbra, 1989 = Bulário, doc. 87, p. 176. O passo do documento que acabámos de citar deve datar-se de 1201 (9 de Maio-26 de Junho). A 22 de Setembro do ano seguinte o rei "Povoador" engrandece o mosteiro de Santa Cruz com uma munificente doação. Trata-se da outorga de vários bens móveis, das granjas de Antanhol, Buarcos e Caceira, bem como de várias vilas. Entre os citados bens móveis avultam os rendimentos obtidos de "omnes tendas quas habent et lucrati fuerint in tota Colimbrid $1 \mathrm{O}$ rei concedia igualmente ao dito mosteiro "omnes pelles agninas suarum ouium et abundantiam pannorum lane (...) et omnes pannos lineos (...) et sufficientiam lane ad filtra facienda." Tudo isto se destinava "fratrum omnium communi uestiario". Além disto, D. Sancho I manifesta neste mesmo documento as suas preocupações com a alimentação dos monges crúzios. Atendendo à sua dieta monástica concede-lhes Buarcos e Caceira "in expensas piscium de quibus per totum annum bene reficiatur refectorium”. Cff. D. D. 5., doc. 144, p. 223-224. Cff. igualmente outras doações de D. Sancho I ao mosteiro de Santa Cruz em D. D. S., does. 5, 10, 22,41,47, 144, 201, 222, 223. 
emergem cenas de uma agressividade impressionante especialmente se tivermos em conta que os seus protagonistas são clérigos. $\mathrm{O}$ eco distante daquela agitação repercute-se ainda hoje, num frémito de vida, quando perpassam sob os nossos olhos os documentos pontifícios onde os conflitos são relatados. $\mathrm{Na}$ verdade, desde a apropriação de privilégios "per subreptionem obtentos" 12 a roubos explícitamente perpetrados "more predonum"13, desde humilhações infligidas a clérigos dependentes da Sé "et ad monasterium ipsum inhoneste deductos"14 até ao "desvio" de defuntos "armata manu" para os sepultar em Santa Cruz, de tudo isto são acusados os soberbos Regrantes.

Os conflitos da Mitra conimbricense com a Coroa resultam principalmente da política régia dirigida por mestre Julião Pais. $O$ influente chanceler havia provavelmente estudado no estrangeiro, talvez em Bolonha. Aqui, em contacto com as ideias que então fervilhavam na Europa, e em particular nesta Universidade, aprendeu como administrar o reino e como conduzi-lo à centralização do poder. Para atingir este resultado havia que atacar privilégios ancestrais, quebrar rotinas, diminuir influências.

Um dos principais alvos desta política foi o clero demasiado poderoso e detentor de vastas riquezas que os ideólogos europeus daquela época, de Arnaldo de Brescia a S. Bernardo e de Pedro Valdo a S. Francisco de Assis, criticavam asperamente ${ }^{15}$.

12 Cfr. bula Ad audientiam apostolatus de Inocêncio III dirigida aos abades de Alcobaça e Seiça e a Femando Mendes, monge daquele mosteiro, ordenando-lhes que, após apuramento da verdade, façam regressar à posse do prelado conimbricense a igreja de Quiaios (c. Figueira da Foz) que os Crúzios detinham indevidamente. Cif. Bulário, doc. 4, p. 7.

13 Bula Gravis querela (1198, Maio 30) dirigida por Inocêncio III aos monges de Alcobaça, Femando Mendes e Pedro Froidiz, ordenando-lhes que resolvam a questão entre o bispo de Coimbra e os Crúzios que tinham devassado e espoliado a vila de Tavarede (c. Figueira da Foz) que era propriedade da Sé daquela cidade. Cfr. Bulário, doc. 17.

14 Cfr. bula Ad audientiam nostram de Inocêncio III, datada de 19 de Novembro de 1198 , dirigida aos abades de Alcobaça e Seiça e ao deão de Lisboa, para que investiguem a queixa do bispo de Coimbra relativamente às violências perpetradas pelo prior de Santa Cruz contra o presbítero e diácono de Arazede (c. Montemor-o-Velho). Cfr. Bulário, doc. 29, p. 39.

15 Sobre Arnaldo de Brescia cfr. F. Vemet in Dictionnaire de Théologie Catholique contenant Vexposé de la Théologie Catholique. Paris : Letouzey et Ané, I, col. 1972. Sobre S. Bernardo vid. CONGAR, Yves - "L'ecclésiologie de Saint Bernard”. In Église et papauté. Paris : Editions du Cerf, 1994, especialmente p. 177. Sobre os Pobres de Lyon e Pedro Valdo, assim como Arnaldo de Brescia, cff. (entre outros) MESTRE GODES, Jesus - Os Cátaros. Origens, desenvolvimento, perseguição, extinção. Cascais : Pergaminho, 2001, p. 66-69. As ideias-chave de S. Francisco podem encontrar-se sintetizadas num trabalho de LE GOFF, Jacques - S. Francisco de Assis. Lisboa : Teorema, 2000, especialmente p. 52-55; 59-64. 
Apesar das munificentes doações régias e dos amplos privilégios outorgados à Catedral de Coimbra, desde a concessão em Maio de $1186^{16}$ de todas as igrejas construídas e a construir na Covilhã e seus termos, à isenção de todo o clero daquela diocese de ir em fossado e quaisquer outras expedições, a não ser contra os mouros que invadissem o país ${ }^{17}$, as relações entre D. Sancho I e Pedro Soares revelam momentos de grande tensão. É provável que o prelado, depois de ter obtido, a 7 de Janeiro de 1199, protecção apostólica para a sua diocese ${ }^{18}$ e especialmente animado pelas vitórias alcançadas contra os Templários e contra os bispos do Porto e da Guarda ${ }^{19}$, se sentisse confiante para afrontar o rei. Mas em breve se aperceberia do pavor $^{20}$ imenso que o monarca lhe causava e das perseguições que lhe poderia mover.

A bula de Inocêncio III - Si diligenter attenderes datada de 23 de Fevereiro de 1211 - dirigida ao rei relata com abundância de pormenores, não só conhecidos na cúria romana ex litteris venerabilis fratris nostris Petri episcopi, mas também ouvidos viva voce do prelado de Coimbra, um conjunto infindável de ofensas gravíssimas de que ele próprio e a sua Catedral haviam sido vítimas. D. Sancho, omissa reverentia Redemptoris, atacava impiedosamente a Igreja da qual - continua Inocêncio III - non oppressor esse debes sed deffensor. Em moldes até aí desconhecidos da jovem monarquia portuguesa, o referido monarca não perdia ocasião para humilhar em tudo o que podia os clérigos expulsando-os de suas casas e colocando nas mesmas outras pessoas. Apreendia-lhes mantimentos e roupas e, ignorando privilégios e liberdades concedidas àqueles pelos seus antecessores (e por ele próprio), e utilizando uma audaciosa intromissão de poder, retirava os benefícios a clérigos canonicamente providos nos mesmos e entregava-os a outros.

As admoestações pontificias que entretanto chegavam a Portugal aconselhavam o rei a moderar os excessos ameaçando-o de, em caso de contumácia, ser declarado inimigo da Igreja. Porém, D. Sancho revelando uma notável

${ }^{16}$ Cfr. D. D. S., doc. 9, p. 12.

17 Idem, ibidem.

18 Bula de Inocêncio III Sacrossanta Romana Ecclesia dirigida ao bispo de Coimbra in Bulário, doc. 36, p. 50-51.

19 As questões litigadas, durante o episcopado de D. Pedro Soares, contra os prelados do Porto e da Guarda, relativamente aos limites das respectivas dioceses acham-se resumidas em VELOSO, Maria Teresa Nobre - D. Afonso II, p. 234-239.

20 Não só o prelado temia D. Sancho I (e os seus oficiais régios), mas também todo o Cabido. É o que afirma o mestre-escola da Sé de Coimbra ao responder, no inquérito de 1252, sobre os motivos que justificavam a aposição forçada do selo capitular no acordo estabelecido entre D. Pedro Soares e os Crúzios - "ob metum portarii regis". 
ousadia para aquela época, responde ao Santo Padre com uma verdadeira atitude de desafío. Não só ignorou os conselhos e ameaças como intensificou as perseguições: coagia clérigos pobres e detentores de parcos rendimentos a manter-lhe cães de caça, caçadores e cavalgaduras; prendia sem culpa formada eclesiásticos atirando-os para cadeias públicas de onde os fazia litigar ante as justiças seculares; recrutava-os para o exército...

O citado diploma de 23 de Fevereiro de 1211 continua o relato das perseguições do monarca denunciando situações gravíssimas: D. Sancho amparava os usurários, protegia os amancebados e os excomungados e a animadversão régia contra o clero e seus bens era de tal ordem que tinha por dia mal-afortunado aquele em que encontrava um eclesiástico ou um religioso. Àqueles que (incluindo o bispo e o Cabido), invocando as suas prerrogativas, se recusassem a pagar tributos, o soberano mandava destruir casas e apreender tudo o que nelas houvesse. Face a esta situação o prelado conimbricense lançou interdito sobre o bispado. Mas a resposta do monarca a tal pena canónica não se fez esperar e galvanizado por uma ira profunda lançou-se, com incontida fúria, sobre os clérigos que, guardando o interdito, se recusassem a celebrar os ofícios divinos diante do rei. A esses infelizes D. Sancho ordenava que lhes arrancassem os olhos mesmo diante dos seus parentes e amigos ${ }^{21}$.

Este acervo de ofensas que o Santo Padre considerava inspiradas nas contestações heréticas de além Pirenéus ${ }^{22}$ tinha responsáveis. Um, o principal, era mestre Julião Pais que (sabia-se na cúria romana) escondia ao rei (ou pelo menos interpretava aliter) o teor dos diplomas pontifícios enviados ao monarca pelo Santo Padre 23 . A outra fonte de inspiração do ódio de D. Sancho I contra o

21 "quod clericos ad mandatum electis qui eam relaxare volebat celebrare nolentes coram propriis parentibus et amicis ut asserebatur eidem exoculari madaveras..." Bulário, doc. 154, p. 296. O castigo de cegueira perpétua que nos deixa hoje horrorizados era comum na Hispânia, quer entre mouros quer entre cristãos, que ousassem atentar contra a autoridade régia. Veja-se, por exemplo, a sanção aplicada no século IX pelo rei Ramiro a Nepociano e a Aldroito que exerciam as funções de "comes palatiï e se voltaram contra o soberano. Cfr. SÁNCHEZ ALBORNOZ, Claudio - Orígenes de la nación Española. El reino de Asturias. Estudios críticos sobre historia del reino de Asturias (selección). Madrid: Sarpe, 1985, p. 201 e 209. No entanto, é provável que por aquela época (primeira metade do século XIII) o uso deste castigo estivesse já em declínio porque Inocêncio III na bula que temos vindo a citar ao referir-se a este assunto classifica-o de "crudelitas". Bulário, doc. 154, p. 296.

22 "Sed et illud quod in eisdem litteris subscripsisti non sapit catholicam puritatem sed haereticam videtur perfidiam exhalare^ ${ }^{\wedge}$ Bulário, doc. 154, p. 297.

${ }^{23}$ Bula Licet venerabilis de Inocêncio III dirigida ao arcebispo de Compostela, a 23 de Fevereiro de 1211, ordenando-lhe que resolva a questão entre o rei de Portugal e o prelado de Coimbra. Ordena igualmente ao Compostelano que mande 1er ao rei as letras apostólicas relativas ao caso do citado bispo visto que o chanceler régio ocultava a verdade ao monarca. Bulário, doc. 155, p. 298. 
prelado e clero conimbricenses era uma feiticeira ${ }^{24}$. Segundo a bula Si diligenter attenderes, uma das causas do redobrar da ira régia teve origem na admoestação feita por D. Pedro Soares que aconselhava aquele rei "ut dimitteresphytonissam quam quotidie consulebas'. Somava-se ainda a tudo isto a proibição régia feita às "personas insuper ecclesiasticas a regno exire et intrare"25.

D. Sancho, sentindo aproximar-se o fim da vida e tendo em conta a insegurança política ainda vigente no país, solicitou ao Santo Padre a confirmação do testamento que elaborara em Outubro de $1210^{26}$. Inocêncio III respondeu-lhe favoravelmente na bula Is qui tangit datada de 27 de Maio de 1211. Apesar do manifesto estado valetudinário do $\mathrm{rei}^{27}$, o Santo Padre não deixa ainda de o admoestar certamente convencido do arrependimento do monarca. A aparente quebra de coerência da política régia tinha porém outros motivos - os interesses do país que o dito soberano deixava a um filho com saúde precária e sobre o carácter do qual tinha algumas dúvidas.

A chegada de D. Afonso II ao trono fez intensificar os conflitos entre a Coroa e a Mitra de Coimbra. Alexandre Herculano, ao mencionar os mesmos, afirma desconhecer-se a causa que os motivou ${ }^{28}$. No entanto, lendo o extenso e pormenorizado inquérito realizado naquela cidade cerca de $1252^{29}$ no qual depõem, como testemunhas presenciais, dignidades, cónegos e outros beneficiados da citada Igreja, ficamos a conhecer exactamente o motivo dessa conflitualidade - o mosteiro de Santa Cruz. O mestre-escola da Sé tendo sido interrogado

24 “Ceterum, in animae tuae periculum detinens phytonissam $\backslash$ Bulário, doc. 154, p. 295.

${ }^{25}$ Bulário, doc. 154, p. 296.

${ }^{26}$ D. D. S., doc. 194.

27 "Zs qui tangit montes et fumigant cor tuum tetigisse videtur ad penitentiam salutarem dum corporali egritudine te affligens ad sanandas spirituales egritudines te induxit quatinus recogitando annos in amaritudine anime tue pro excessibus tuis quibus Creatorem tuum multipliciter offendisti offerres ei sacrificium vespertinumBulário, doc. 158, p. 303.

${ }^{28}$ História de Portugal desde o começo da monarquia até ao fim do reinado de D. Afonso III. Notas críticas de José Mattoso. Tomo III. Lisboa : Bertrand, 1980, p. 306.

29 Este inquérito que lemos, transcrevemos na íntegra e tencionamos publicar em breve, relata diversos acontecimentos ocorridos em Portugal entre os reinados de D. Sancho I e o advento de D. Afonso III. É uma verdadeira crónica dos problemas políticos, sociais e religiosos que ensombraram o país naquela época. Embora aquele inquérito não esteja explícitamente datado, sabemos que se realizou cerca de 1252 (ou 1253) porque o mestre-escola de Coimbra ao ser interrogado sobre "quanti anni sunt elapsi a tempore quo cessit episcopus Petrus usque nunc respondit quodXX. ${ }^{\text {ti }}$ anni et amplius '. Inquirido ainda sobre a data em que teria ocorrido a cessação de ftmções do bispo D. Pedro Soares respondeu "quod in mense Maif. Na verdade, este testemunho é fidedigno porque, a 25 de Junho de 1232, Gregorio IX na bula Tanta est clavis dirigida ao arcebispo de Braga referindo-se ao prelado de Coimbra di-lo quondam episcopus. Cff. esta bula em COSTA, António Domingues de Sousa - Mestre Silvestre e Mestre Vicente, p. 188, nota 304. Quando citarmos aquele documento designá-lo-emos por Inquérito. 
sobre a razão pela qual D. Pedro Soares se tinha exilado respondeu que tal se devia ao medo que o prelado tinha do rei. E o inquiridor insiste: "qualis erat metus regis". A citada testemunha esclarece: "quod [ipse] episcopus timebat sibi et suis et bona sua erant ocupata per regem ita quod [episcopus] fere nihil persipiebat de episcopatu". Acrescenta ainda "quod rex ista faciebat propter monasterium Sancte Crucis"10.

$\mathrm{Na}$ realidade, D. Pedro Soares não se conformava com a resposta favorável dada ao recurso da sentença proferida em 1201 pelo bispo e deão de Samora e o deão de Orense, legados apostólicos na causa ventilada entre a Sé de Coimbra e o Mosteiro de Santa Cruz desta cidade. Inocêncio III, atendendo às reclamações dos Crúzios, moderara significativamente, com prejuízo para a Catedral de Coimbra, o que fora estabelecido pelos citados juízes apostólicos 303031 . Por isso, o prelado aproveitando a ida à cúria romana por ocasião do IV concílio lateranense, volta a apresentar ao Santo Padre as suas queixas contra o mosteiro de Santa Cruz. Terminadas as actividades conciliares que demoraram o dito bispo cerca de dezassete meses fora do reino, regressa a Portugal munido dos diplomas pontificios que lhe iriam permitir repor, assim cria, a justiça. Espera-o, porém, uma amarga surpresa. Na alcáçova de Coimbra ergue-se, irado e temível, D. Afonso II que sob a assustadora ameaça de condenar à cegueira perpétua o cavaleiro Martinho Soares, irmão do prelado, coage este a ceder aos Crúzios Buarcos e Caceira ${ }^{32}$. O bispo tentou talvez ainda reagir apoiando a intervenção do dominicano, Frei Soeiro Gomes, na diocese de Coimbra concedendo-lhe, não só direito a pregar, como autorização e poder para compelir e emendar pela força todos os excessos. Apesar das leis de Soeiro Gomes estarem certamente de acordo com as determinações canónicas do IV concílio de Latrão relativas às heresias, aquelas não deixavam de representar uma ingerência na autoridade régia ${ }^{33}$.

${ }^{30}$ Cfr. Inquérito. Vid. Igualmente VASCONCELLOS, M. Ribeiro de - "Notícia histórica..." p. 10 , nota 4 .

31 Bula Cum olim de Inocêncio III dirigida ao bispo D. Pedro de Coimbra a 26 de Junho de 1203. O Santo Padre, após historiar sinteticamente as diversas fases da questão litigada entre o prelado e o mosteiro de Santa Cruz, põe termo àquela moderando, de modo significativo a favor do mosteiro, a sentença proferida em 1201 pelo bispo e deão de Samora e pelo deão de Orense. Cff. VELOSO, Maria Teresa Nobre - D. Afonso II, p. 247-249.

32 São concordes neste ponto os testemunhos do cónego mestre Bartolomeu e de João Martins, prior de S. Bartolomeu de Coimbra. Afirma o primeiro, em resposta ao inquiridor, que ouvira dizer a Frei Gonçalo, monge dominicano, que D. Pedro Soares cedera os direitos sobre Caceira e Buarcos com medo que o rei mandasse cegar seu irmão. Interrogada sobre a mesma questão, a segunda testemunha respondeu que o bispo de Coimbra procedera daquele modo "ut liberaret fratrem suum de captione regis".

33 Cff. VELOSO, Maria Teresa Nobre - D. Afonso II, p. 134-136. 
D. Afonso II agita-se mais temível do que nunca e, além de anular todos os decretos do referido dominicano, submete D. Pedro Soares a urna extrema humilhação: prende-o durante vários meses no paço episcopal onde ninguém podia entrar para o servir. Todas as testemunhas que viram e presenciaram estes acontecimentos a eles se referem, emocionadas, com mais ou menos pormenores. O chantre de Coimbra inquirido sobre esta questão "dixit quod fuit inclusus (o bispo) per regem Alfonsum secundum Colimbrie in domibus suis per IIII. or menses vel V.e ut credit et nullus serviens laicus erat ausus ei servire sed clerici". Interrogado sobre o modo como tinha conhecimento destas questões respondeu com toda a clareza: "vidit et presens fuit". E o inquiridor insistiu perguntando à referida testemunha como é que sabia que tinha sido o rei a prender o bispo. Então, o referido chantre ao responder acrescentou um pormenor extraordinário que documenta a temível autoridade real: "audivit regem ista verba: hic est falco et ibi ardea, vertendo se ad domum episcopi; si se moverit falco capiet eam (intelligens se nominare per falconem et per ardeam episcopum)".

Ao cabo de quatro ou cinco meses de reclusão - continua o mestre-escola conimbricense - o prelado "exivit inde cum barba prolixa et cruce signatus" ${ }^{34}$. *VII

34 Este depoimento é confirmado pelas outras testemunhas. O mestre-escola inquirido sobre a prisão de D. Pedro Soares respondeu "quod fuit inclusus per regem per octo vel per VIIII.em menses. Interrogatus quomodo scit respondit quia vidit et passus fuit. Interrogatus quomodo scit quod per regem fuit inclusus respondit quod audivit et credit et erat publicum et notorium. Interrogatus per quem regem respondit quod per regem domnum Alfonsum patrem istius $\backslash$ Este relato é corroborado pelo prior de S. Bartolomeu de Coimbra, João Martins, que foi "doméstico" do bispo durante dois anos: "dixit quod dictus episcopus $\mathrm{P}$ (etrus) fuit inclusus et audivit quod timore regis et vidit quod nullus erat ausus ei servire nisi soli clerici et fuit tunc inclusus ut credit per

VII vel IX. ${ }^{\mathrm{m}}$ menses et vidit tunc episcopum $<$ habentem $>$ barbam prolixam exis tentem in domo sua Colimbrie. Interrogatus si libere et secure poterat exire respondit quod nescit. Interrogatus quomodo scit respondit quod rex minabatur ei. Interrogatus si erat presens rex in civitate tempore inclusionis respondit quod sic et dixit quod ista inclusio fuit publica et notoria $\backslash \mathrm{O}$ cónego João Femandes, que também havia sido "doméstico" do bispo D. Pedro, coloca no seu depoimento uma particular ênfase no ódio que o rei nutria pelo prelado: "Interrogatus quomodo scit quod per regem erat inclusus respondit quod comuniter dissebatur in civitate Colimbriense quod propter timorem regis qui inimicabatur ei erat sic inclusus. Interrogatus si poterat exire libere respondit quod credit quod non propter hodium regis. Interrogatus si rex fuit in civitate toto tempore dicte reclusionis respondit si non recolere. Interrogatus si homines armatis erant in circuitu domus ad inclusionem ipsius respondit quod non vidit”. O deão de Coimbra inquirido sobre este mesmo assunto respondeu de modo semelhante ao das testemunhas anteriores, mas acrescentando um ou outro pormenor: "dixit quod non vidit eum inclusum sed publica fama erat in civitate Colimbrie in qua iste testis tunc morabatur quod timor regis non ausus exire de domu sua et quod servientes laici non erant ausi ei servire quia ut dicebatur rex minatus fuerat eis si ei servirent et quod clerici tamen serviebant ei et quidam clericus dixit publice ipse teste presente vade emere victualia domino episcopo quia nullus laicus est ausus ei emere (...) Interrogatus quanto tempore fuit in isto stato respondit quod per annum ut credit". 
Estes sinais exteriores documentam a mudança interior que entretanto se operara.

Quando D. Pedro Soares saiu do cativeiro era outro homem. Assustado e humilhado, concluíra que nem o múnus que exercia nem as sanções canónicas que fulminasse contra o rei tinham qualquer efeito. Por aquela altura deixara também de acreditar cegamente no poder de Roma que em momentos de aflição e de emergência se poderia revelar demasiado distante e cujas decisões nem sempre primavam pela justiça. O prelado conimbricense, cansado de tantas lutas e atingido na sua dignidade, opta por outra estratégia: pactuar com o rei; ser-lhe submisso. Já nada tem a perder. Os anos de episcopado - como ele próprio dirá 353637 - pesavam excessivamente. Abandona o zelo eclesiástico inicial e entrega-se à vontade da Coroa com uma fidelidade que irrita os clérigos que se sentem prejudicados, especialmente o Cabido catedralicio.

Este inicia uma campanha com o fim de o afastar. $\mathrm{O}$ argumento utilizado é a loucura ${ }^{36}{ }^{37}$. O bispo que de um modo tão ostensivo tinha abandonado a defesa dos interesses da Catedral só podia estar mentecapto, acham os cónegos.

0 inquérito realizado cerca de vinte anos após a renúncia do prelado à Mitra é profundamente esclarecedor. Nele se encontra documentado, com clareza, todo o processo que levou ao epílogo de 1232. As testemunhas, dignidades, cónegos e outros beneficiados da Igreja de Coimbra, explicam pormenorizadamente as razões pelas quais acham que o bispo estava sem juízo:

1 - O aspecto físico. Bastava reparar nos olhos do prelado - afirma mestre Bartolomeu, cónego de Coimbra - para concluir que o bispo D. Pedro 'fluit furiosus et non erat sane mentis" 31 .

2-0 modo de falar. Segundo depoimento de algumas testemunhas, D. Pedro Soares apresenta um discurso incoerente. João Martins, prior de S. Bartolomeu de Coimbra que fora "doméstico" do prelado durante dois anos, inquirido sobre

35 Cfr. bula Ex parte venerabilis enviada a 31 de Julho de 1228 por Gregorio IX ao legado João de Abeville recomendando-lhe que acelerasse o processo relacionado com o preenchimento da vaga da diocese da Guarda, sem bispo há dois anos. Este facto atrasava a conclusão da demanda relativa aos limites desta diocese e da Conimbricense. Por isso, o bispo desta cidade queixava-se

- diz o Santo Padre - "cwm tringinta fere annis pro eadem causa laborans jam confectus sit senio et de pluribus sententiis pro se latis nullum commodum reportant". Vid. COSTA, Antonio Domingues de Sousa - Mestre Silvestre e Mestre Vicente, p. 161-162.

36 Este argumento não era novo. O mesmo já se tinha invocado quando D. Afonso II contestou, por intermédio dos seus juristas entre os quais avulta a figura de mestre Silvestre, o testamento de D. Sancho I relativamente às doações feitas às irmãs daquele rei. A bula de Inocêncio III, Dilecti filii fratres, de 23 de Julho de 1217, repete o dito argumento segundo o qual D. Sancho I "quia tempore quo concessit compos non fuerat mentis sue". Cff. VELOSO, Maria Teresa Nobre

- D. Afonso II, p. 15.

${ }^{37}$ Inquérito, depoimento de mestre Bartolomeu. 
aquela questão respondeu "quod vidit eum indiscrete loquentem | Esclareceu ainda que "vidit eum loquentem multa vana et dicentem non dicenda"38.

3-0 comportamento. D. Pedro Soares agia - segundo alguns dos inquiridos de modo irracional.

O cónego mestre Bartolomeu e o cónego Soeiro Geraldes relatam o modo como o prelado se comportou na altura em que se dirigiu em peregrinação a

S. Vicente de Fora ${ }^{39}$. Já no regresso, cerca de Alenquer, abandonara a estrada e metera-se pelo meio das umas vinhas sem que fosse possível alcançá-lo.

Soeiro Geraldes informa ainda que o bispo lhe prometera vir jantar com ele na sua casa de Alenquer. Porém, saindo-lhe ao encontro "ipse episcopus dimissa via publica ivit per vineas et sic nollens ire post eum non potuit eum attingere । No regresso a Coimbra, Soeiro Geraldes conversou com D. Pedro Soares sobre este assunto. O prelado respondeu-lhe " $<$ de eis $>$ non se recordari" 40 .

O cónego mestre Bartolomeu relata ainda outro episódio ilustrativo - segundo cria - da demência do prelado: um dia, saíra D. Pedro Soares de seu paço montado em uma mula logo seguido pelos criados. No entanto, estes só o puderam alcançar perto da Ferraria (Fomos - Coimbra) onde o detiveram segurando o freio do animal que estacando subitamente projectou o bispo. Para se recompor da queda, buscou assento numa escada. O povo, curioso com aquela movimen-

38 O mesmo testemunho é corroborado pelo cónego João Femandes “audivit eum dicentem multa indiscrete et facientem et quando t/r]atabat causas frequenter dicebat contra se ita quod advocati instabat penes eum quando non iret ad causam". Mais adiante o inquiridor perguntou novamente à testemunha "quomodo scit episcopus erat inutilis et inabilis ecclesie". O cónego João Femandes respondeu que o ouvira dizer "turpia verba". De igual modo o deão de Coimbra interrogado sobre esta questão do discurso incoerente do bispo respondeu "si dicatur sandeu homo positus extra mentem talem vidit eum per tres annos ante violacionem interdicti si vero dicatur sandeu homo qui prohicit lapides non vidit eum talem".

39 A devoção ao mártir valenciano foi muito divulgada durante a Idade Média. Eram famosas as peregrinações a S. Vicente do Cabo. Cff. MARTINS, Mário - "Peregrinações e livros de milagres na nossa Idade Média", in Revista Portuguesa de História. Tomo V. Homenagem a Gama Barros, vol. II. Coimbra : Instituto de Estudos Históricos Dr. António de Vasconcelos, 1951, p. 103-114. No entanto, a grande popularidade deste santo (cuja fama dos milagres chegou a Coimbra, à Galiza, a Lafoes...) ocorreu quando as suas relíquias foram trasladadas para Lisboa em 1173 por D. Afonso Henriques. Os restos mortais do Santo de Valência trouxeram à cidade recém-conquistada a aura de prestígio de que ainda carecia. Esta preocupação do rei já o tinha levado a prestar uma especial atenção às relíquias dos santos tradicionais de Lisboa - Veríssimo, Máximo e Júlia em honra dos quais mandara construir uma casa nesta cidade para que aí repousassem condignamente os seus corpos até se construir o mosteiro de Santos. Cff. D. D. S., doc. 71. É neste ambiente de grande devoção àquele mártir, promovido agora a padroeiro de Lisboa, que D. Pedro Soares se desloca até à cidade do Tejo. Cff. S. Vicente de Lisboa e seus milagres medievais. Editores: NASCIMENTO, Aires Augusto; GOMES, Saúl António. Lisboa: Edições Didaskalia, 1988, p. 8-16.

${ }^{40}$ Inquérito, depoimentos dos cónegos mestre Bartolomeu e Soeiro Geraldes. 
tação inusitada de homens e cavalos, foi-se juntando. Os criados do bispo colocaram-no, de novo, sobre o dorso do animal e reconduziram-no ao paço. Inconformado, D. Pedro Soares dirigindo-se àquela pequena multidão de adultos e crianças protestava: - "videte quomodo ducunt me captum et ego excomunico eos et sint excominicati". Por este motivo - continua mestre Bartolomeu "videbatur ei episcopum non essere tunc sane mentis"41.

A incondicional fidelidade ao rei, e o consequente abandono dos interesses eclesiásticos, patenteiam-se, de igual modo, na atitude que assumiu aquando do litígio entre D. Afonso II e o arcebispo de Braga. Este, que enfrentara o monarca num grave conflito em defesa das liberdades eclesiásticas, viu-se forçado, face à insegurança que o país lhe oferecia, a buscar refugio no reino de Leão. Por isso, a 21 de Dezembro de 1220, o papa Honorio III dirige a bula Certantibus pro justitia a todos os sufragáneos de Braga ordenando-lhes que contribuíssem com um subsídio destinado à manutenção do prelado ${ }^{42}$. D. Pedro Soares parece ter ignorado completamente o problema vivido pelo Bracarense. Assim o confirma o texto da bula Sperabamus hactenus que o papa Honorio III lhe dirige a 23 de Dezembro de 1220.

Neste diploma, o Santo Padre repreende-o por ter abandonado o arcebispo de Braga e aconselha-o a pôr-se ao lado de D. Estêvão Soares da Silva na luta que este travava contra o rei de Portugal sob pena de confirmar a excomunhão que aquele lançara sobre o citado bispo conimbricense.

Relendo o texto da dita bula percebe-se que a cúria romana já tem conhecimento da nova atitude de D. Pedro Soares que pendia ostensivamente para os interesses régios: "Sperabamus hactenus - escreve o Santo Padre dirigindo-se ao prelado de Coimbra - quod esses in domo Domini columpna immobilis et erecta ut non solum innitentes tibi debiles sustentares verum etiam esses terrori ascendentibus ex adverso. Mas - continua Honorio III - es facilis ventiflamine agitata"43.

41 "Et audivit quod episcopus predictus solus exivit de domo sua in equitatura sua et venit usque ad Ferariam et sui in secuti sunt eum et ibi detinuerunt eum per frenum mule sue et ipse projecit se de mula in terra et sedit in quadam scala que ibi erat et multi homines et parvi ibi congregati sunt ad eum et sui posuerunt eum super ipsa mula et deduxerunt eum ad domus suas et ipse veniebat dicendo: - videte quomodo ducunt me captum et ego excomunico eos et sint excomunicati - et per hoc videbatur ei episcopum non essere tunc sane mentis

42 Sobre estas questões, cfr. VELOSO, Maria Teresa Nobre - D. Afonso //, p. 136-153 e especialmente p. 147.

43 E o Santo Padre continua nesta bula a fazer eco das queixas do Bracarense: "idem archiepiscopus sentiens ex hoc regem commotum, auxilium tuum fiducialiter imploravit, cum frater qui a fratre iunatur sit uelut civitas communita. Sed, sicut idem archiepiscopus nobis exposuit, licet illud te prestiturum sibi iuraris, fidem tamen tuam irritam faciens, eum immo teipsum nequiterfeffelisti, non sibi sed regi non sine nota proditoris dampnabiliter adherendo $\backslash$ Cfr. COSTA, Antonio Domingues de Sousa - Mestre Silvestre e Mestre Vicente, p. 101, nota 202. 
O desvio máximo de comportamento ocorreu, porém, quando D. Pedro Soares, em total sincronía com os interesses do monarca, ignorou ostensivamente o interdito lançado sobre o rei pelos delegados apostólicos - o bispo, o arcediago e o mestre-escola de Orense - comissionados por Honório III para este fim, em razão do conflito havido entre a Coroa e a Mitra olissiponense.

O rei de Portugal e o bispo de Lisboa mantinham há vários anos uma séria contenda. D. Soeiro, prelado lisboeta, "espécie de homem de armas mascarado com vestes sacerdotais" - como o caracteriza Alexandre Herculano ${ }^{44}$ - tinha ganho prestígio com a colaboração dada na conquista de Alcácer do Sal45. Porém, a perseguição de que ele próprio e a sua diocese foram alvos, quer durante o reinado de D. Afonso II, quer no de D. Sancho II, obrigaram D. Soeiro a exilar-se (1226-1231) e a buscar junto da cúria romana o apoio e a protecção que em Portugal lhe faltavam. As insistentes queixas apresentadas em Roma levaram Honório III a prestar-lhe atenção e, em consequência disso, a admoestar e ameaçar o soberano português.

A 16 de Janeiro de 1224, o Santo Padre dirige a D. Sancho II a bula Optamus fili karissimi. Nela relata pormenorizadamente os agravos de que o prelado de Lisboa se queixava entre os quais avultam as perseguições contra os clérigos, não só aqueles cujo comportamento era devasso, mas também todos os outros. Além disso, noticia a tensão vivida, naquela diocese, entre cristãos e judeus motivada pelo notório sucesso destes últimos na administração das rendas públicas ao arrepio daquilo que impunha a legislação conciliar ${ }^{46}$.

D. Sancho II, apesar das promessas (certamente não cumpridas) no sentido de manter a incolumidade do bispo Soeiro e moderar as perseguições ao clero, acabará por ser fulminado pelos referidos delegados apostólicos com o interdito. É o que se depreende do depoimento do deão de Coimbra no inquérito de 1252: interrogado sobre por quem tinha sido lançado o interdito respondeu "per judices delegatos Sedis Apostolice in causa que vertebatur inter episcopum Ulixbonensem et regem Portugalensem coram episcopo Auriensis et suis conjudicibus".

${ }^{44}$ História de Portugal, Tomo III, p. 412.

${ }^{45}$ Sobre esta colaboração, cfr. VELOSO, Maria Teresa Nobre - D. Afonso II, p. 128-129.

46 "et judeos, quos contra statuta concilii generalis in suis officiis non verebatur preponere christianis, ipsi episcopo pro eo quod circa judeos statutum ipsius concilii de signis portandis, sicut a nobis receperat in mandatis, observari precepit, in eos qui exercent commercia cum ipsis judeis servare statutum hujusmodi contempnentibus excommunicationis sententia promulgata, regales decimas pro sua voluntate subtraxit et ecclesiarum terciis spoliavit eundem, Christianos prefato statuto concilii et excommunicationis sententia supra dicta contemptis, exercere cum ipsis judeis commercia non absque grande et gravi apostolice sedis injuria compellendoCfr. COSTA, Antonio Domingues de Sousa - Mestre Silvestre e Mestre Vicente, p. 144-145, nota 218. 
É neste ambiente de agitação que antecede já a "guerra et turbatio"*1 (que levará mais tarde à deposição de D. Sancho II) que o prelado de Coimbra, ignorando por completo aquela grave pena canónica, se apresenta, a 8 de Setembro de 1231, na sua Catedral a celebrar uma das festas litúrgicas mais solenes - a Natividade da Virgem. Tal desassombro - afirma o mestre-escola conimbricense - só pode ser explicado pela demência.

Esta justificava outras acções como as que o bispo praticou ao espoliar os cónegos que se recusavam a compactuar com o dito prelado nesta atitude; ou aquelas que, pelo mesmo motivo - afirma o deão conimbricense - "dabat regi illos pro hereticis $" * \%$.

A reacção do Cabido de Coimbra contra o seu pastor não se fez esperar, pois cerca de nove meses mais tarde (25 de Junho de 1232) D. Pedro Soares renunciava ao bispado nas mãos do Santo Padre.

Apesar da gravidade da falta cometida - escreve Gregorio IX na bula Tanta est clavis dirigida naquela data ao arcebispo de Braga - o prelado conimbricense, tendo reconhecido publicamente 4748474849 os seus erros, foi perdoado porque "non judicium sed misericordia postulans in manibus nostris spontanea cesserit voluntate". Além disso - continua Gregorio IX - nós tivemos compaixão dele devido à sua "simplicitati et senectuti" 50 .

$\mathrm{O}$ argumento do desgaste provocado por muitos anos de exercício do múnus episcopal em circunstâncias extremamente duras foi compreendido pelo Santo Padre tanto mais que D. Pedro Soares já em 1223 o tinha invocado.

A benignidade com que Gregorio IX tratou o prelado de Coimbra patenteia-se na bula Licet venerabilis de 28 de Julho de 1232. Nesta data, o Santo Padre - "nolentes ipsum in episcopalis ordinis opprobrium mendicare" - dirigindo-se

47 O cónego João Femandes depondo, como testemunha, no inquérito de c. 1252 disse que "tempore <regis> domni Sancii <secundî> fuit tanta guerra et turbacio in regno quod nullus erat ausus exire a civitate Colimbriense et si exibat spoliabatur et capiebatur et audivit quod in aliis partibus regni ita fiebat et hoc erat publicum et notorium".

48 O mestre-escola interrogado sobre a verdade da violação do interdito feita por D. Pedro Soares respondeu “quod violavit interdictum et spoliavit canonicos qui sibi noluerunt consentire (...). Interrogatus de tempore respondit quod sunt $X X$ unnus anni. Interrogatus de mense respondit quod in mense Sebtembris in vigilia vel in die Nativitatis Beate Marie I $O$ deão inquirido sobre o mesmo assunto completa o testemunho do mestre-escola informando que o prelado violava o interdito "et spoliavit dignitatibus prehendis et beneficiis personas et canonicos qui noluerint sibi consentire in violacionem interdicti et substituit alios (...) et audivit quod dabat regi illos pro hereticis qui noluerunt cum eo violare interdictum".

49 “que omnia idem episcopus in nostra et fratrum nostrorum presentía publice recognovit”. Cff. COSTA, Antonio Domingues de Sousa - Mestre Silvestre e Mestre Vicente, p. 189, nota 304.

50 Idem, ibidem. 
ao arcebispo de Braga ordena que providencie a D. Pedro Soares uma vida digna condizente com as funções que exercera. Por isso, ficava aquele autorizado a utilizar rendimentos da Mesa episcopal de Coimbra e a facultar àquele bispo dois clérigos, três criados e duas cavalgaduras ${ }^{51}$.

O longo episcopado de D. Pedro Soares ilustra duas questões essenciais:

a) $\mathrm{O}$ dilatado tempo de exercício de funções, particularmente se o seu titular está exposto a grande pressão, revela-se contraproducente.

b) A efemeridade da obra humana. O prelado de Coimbra foi um estrénuo defensor das liberdades eclesiásticas. Dos soberbos Templários aos arrogantes Crúzios, da orgulhosa ex-rainha de Leão, D. Teresa, aos poderosos bispos cujas dioceses faziam limite com a de Coimbra até ao enfrentamento com o rei de Portugal, com todos litigou o bispo conimbricense com um empenho que cerca de meia centena de bulas que lhe são dirigidas comprova amplamente. Além disso, doou à sua Catedral muitos bens de que era proprietário em Espinho (c. Condeixa-a-Nova) e em Coimbra, particularmente vinhas, olivais e laranjais situados no actual Penedo da Saudade ${ }^{52}$. Dividiu, a 17 de Março de 1210, as rendas da Mitra e do Cabido ficando dois terços para aquela e um terço para este. Assim terminou, "post multas controversias", uma questão que se arrastava já de episcopados anteriores ${ }^{53}$. Beneficiou os "viros litteratus <in> ecclesia sua" 54 protegendo a cultura. No entanto, a memória que dignidades, cónegos e outros beneficiados da Igreja-Mãe de Coimbra deixam expressa no inquérito de 1252 relativamente ao governo de D. Pedro Soares sintetiza-se em duas palavras: inutilis et dampnosus ${ }^{55}$. A sua administração - afirma o cónego João Femandes respondendo como testemunha ao referido inquérito - foi deficiente. Instado a explicar as suas razões, o dito João Femandes respondeu que o prelado "frivolas expensas faciebat cum personis superfulis et inutilibus que dabant ei mala consilia"-, e o deão conimbricense conclui classificando-o de "homo sandeu".

Por tudo isto talvez não seja surpreendente que D. Pedro Soares tenha eleito, com toda a lucidez, para sua sepultura o mosteiro de Santa Cruz.

51 "per apostolica scripta mandamus quatinus de bonis ad mensam colimbriens is pertinentibus facias per seipso duobus clericis et tribus servientibus ac duabus equitaturis provisionem congruam assignari”. Cfr. COSTA, António Domingues de Sousa - ob. cit., p. 190, nota 306.

» Cfr. L. K., T. I, p. 306-307; L K.., T. II, p. 322.

53 VASCONCELLOS, Miguel Ribeiro de - "Notícia histórica...", p. 5 e doc. 6, p. 28-29; Livro das Vidas dos bispos..., nova edição, p. 85.

54 Depoimento do mestre-escola ao Inquérito c. 1252.

55 Depoimento de João Martins, prior de S. Bartolomeu de Coimbra, ao Inquérito de c. 1252. 